\title{
Computer Aided Drug Designing Using Phytochemicals- Bacoside A3 and Myricetin and Nitric Oxide Donors- S-Nitroso-N-Acetylpenicillamine and Nitroglycerin as a Potential Treatment of Pancreatic Cancer
}

\section{N.S. Desai* and Mohini Gore}

Department of Biotechnology \& Bioinformatics, Padmashree Dr. D.Y. Patil University, Sect-15/50 C.B.D. Belapur, Navi Mumbai 400614 India

\begin{abstract}
Pancreatic cancer is one of the most aggressive malignant cancers with a high metastatic rate and a very poor prognosis. Tissue Transglutaminase 2 (TG2), Matrix metalloproteinase 2 (MMP2) and Matrix metalloproteinase 9 (MMP9) are up regulated in pancreatic cancer and have been implicated in cancer metastasis. Nitric oxide (NO) can inhibit enzymatic activity of TG2. Inhibition of TG2 by NO donors- nitroglycerin and S-nitroso-N-acetylpenicillamine may offer a novel strategy for anticancer therapy. Phytochemicals namely, Bacoside A3 and Myricetin have an inhibitory effect on proteins MMP2 and MMP9. Computer aided drug designing is being used extensively to establish potential drugs for the treatment and containment of various diseases including cancer. In this in- silico study, we have generated $3 \mathrm{D}$ structures of TG2, MMP2 and MMP9 using Homology Modeling. Chemical structures of nitroglycerin, S-nitroso-N-acetylpenicillamine and Bacoside A3-Myricetin combination were drawn using chemsketch. Chemical structures of Nitroglycerin and S-nitroso-N-acetylpenicillamine were successfully docked with the 3D structure of TG2. Similarly the chemical structure of Bacoside A3-Myricetin combination was successfully docked with the 3D structures of MMP2 and MMP9.
\end{abstract}

Keywords: Bacoside A3; Myricetin; Nitroglycerin; Pancreatic cancer; S-nitroso-N-acetylpenicillamine

Abbreviations: TG2: Tissue Transglutaminase 2; MMP2: Matrix Metalloproteinase 2; MMP9: Matrix Metalloproteinase 9; NO: Nitric Oxide

\section{Introduction}

The incidence of pancreatic cancer has gradually increased since the 20th century [1]. It is one of the most aggressive human malignancies, with a very poor prognosis. It is one of the leading causes of cancer death in many countries. It has a high metastatic rate and is an almost uniformly lethal disease in humans [2,3]. Almost all pancreatic cancers are adenocarcinomas of the ductal epithelium. More than two thirds of pancreatic cancers occur in the head of the pancreas [4]. Pancreatic serous cystadenomas account for $1-2 \%$ of all exocrine pancreatic tumors, and endocrine tumors account for $1-2 \%$ of all pancreatic neoplasms [5]. The World Health Organization (WHO) recognizes several histomorphologic variants of ductal adenocarcinoma, including mucinous noncystic carcinoma, signet ring carcinoma, adenosquamous carcinoma, undifferentiated (anaplastic) carcinoma, undifferentiated carcinoma with osteoclast-like giant cells and mixed ductal-endocrine carcinoma [6].

Cancer of the pancreas is the sixth most common cancer and fourth cause of death from cancer (22\% of deaths among gastrointestinal cancers). Pancreatic cancer is associated with a poor prognosis, with less than $5 \%$ of patients surviving 5 years after the diagnosis. Surgical resection remains the only chance for curative therapy in these patients [1]. For all the stages combined, the 1- and 5-year survival rates are only $23 \%$ and $5 \%$, respectively. The prognosis is even poorer for patients with advanced pancreatic cancer. At the time of diagnosis, approximately half of the patients have metastases, and their median overall survival (OS) with treatment is around 6 months; whereas approximately one third of patients diagnosed with locally advanced disease have an OS ranging between 6 and 9 months. Only 15\%-20\% of patients are eligible for surgery at diagnosis. Only about $20 \%$ of surgically resected patients with localized disease will survive 5 years [7]. The cancer's lethal nature stems from its propensity to rapidly disseminate to the lymphatic system and distant organs. This aggressive biology and resistance to conventional and targeted therapeutic agents leads to a typical clinical presentation of incurable disease at the time of diagnosis $[1,3,8,9]$. Only $16 \%$ of patients initially present a disease confined to the pancreas (stage I). Thus, of patients seen, $85 \%-90 \%$ have surgically unresectable tumors at the time of diagnosis [1]. Invasion and metastasis are major factors underlying cancer morbidity and mortality [10]. It is estimated that more than $90 \%$ of human cancer deaths result from metastasis, a complex process in which the cells from a primary tumor successfully invade and colonize a distant organ [11]. Drug resistance and metastasis are major impediments for the successful treatment of cancer [12]. There is a clear need for better systemic treatments [7].

TG 2 is a calcium-dependent enzyme that catalyzes the formation of covalent bonds between free amine groups in one protein and protein-bound glutamines of another, creating highly cross-linked protein complexes. TG 2 has been associated with certain pathologic conditions including certain cancers [13]. Several studies have shown that TG2expression is up-regulated in drug-resistant and metastatic cancer cells and cell lines. The increased expression of TG2 in drug-

*Corresponding author: N.S. Desai, Department of Biotechnology \& Bioinformatics Padmashree Dr. D.Y. Patil University, Sect-15/50 C.B. D. Belapur, Navi Mumbai 400614 India, Tel: +91+22+39286175, E-mail: neetindesai@gmail.com

Received November 05, 2011; Accepted December 24, 2011; Published December 29, 2011

Citation: Desai NS, Gore M (2012) Computer Aided Drug Designing Using Phytochemicals- Bacoside A3 and Myricetin and Nitric Oxide Donors- S-Nitroso$\mathrm{N}$-Acetylpenicillamine and Nitroglycerin as a Potential Treatment of Pancreatic Cancer. J Comput Sci Syst Biol 5: 001-008. doi:10.4172/jcsb.1000083

Copyright: @ 2012 Desai NS, et al. This is an open-access article distributed under the terms of the Creative Commons Attribution License,which permits unrestricted use, distribution, and reproduction in any medium, provided the original author and source are credited. 
Citation: Desai NS, Gore M (2012) Computer Aided Drug Designing Using Phytochemicals- Bacoside A3 and Myricetin and Nitric Oxide DonorsS-Nitroso-N-Acetylpenicillamine and Nitroglycerin as a Potential Treatment of Pancreatic Cancer. J Comput Sci Syst Biol 5: 001-008. doi:10.4172/jcsb. 1000083

resistant and metastatic cancer cells was linked to their increased resistance to apoptosis [14-17]. The expression of TG 2 is elevated in the majority of pancreatic ductal adenocaricnoma (PDA) tumors and cell lines [18-20]. Elevated expression of TG2 in pancreatic cancer cells has been implicated in the development of drug resistance, metastatic phenotype and poor patient prognosis [21]. Down-regulation of TG2 expression was associated with the increased sensitivity of cancer cells to apoptotic stimuli and reversal of the drug-resistant phenotype $[19,22]$. TG2 appears to be a promising target for containment and treatment of this formidable disease $[18,19,21]$. As per studies on the regulation, a novel function of TG2 in autophagy, and its possible role in tumorigenesis and in reducing chemosensitivity of pancreatic cancer cells, which are virtually resistant to standard chemotherapy and radiation, suggest that TG2 may serve as an excellent therapeutic target for induction of autophagic cell death in pancreatic cancer and other solid tumors over expressing TG2 [13,18,21].

MMPs are implicated in a wide range of physiological and pathological processes, including morphogenesis, wound healing, angiogenesis, inflammation, and cancer [23]. MMPs are upregulated in virtually all human and animal tumors and cell lines. MMPs, especially those capable of cleaving type IV basement membrane collagen (MMP-2 and -9) were considered to be ideal targets for drug development [24]. MMPs are up-regulated in almost every type of human cancer, and their expression is often associated with poor survival. MMPs promote cancer progression by enhancing tumor cell growth, migration, invasion, metastasis, and angiogenesis. These diverse effects are achieved through the cleavage of a broad range of substrates, including not only structural components of the extracellular matrix (ECM) but also growth-factor-binding proteins, growth-factor precursors, receptor tyrosine kinases, cell-adhesion molecules, and other proteases [25]. MMPs play an important role in the extracellular matrix degradation that is an essential step in tumor invasion and metastases [26-29]. Their elevated expression has been associated with poor prognosis [29]. The expression of MMP-9 in the neoplastic and inflammatory cells increased with more advance tumor stage, depth of tumor invasion and presence of lymph node as well as distant metastases [27].

\section{Chemicals used for this in-silico study}

NO is a gaseous neurotransmitter, a vasodilator and paracrine regulator. In the pancreas, NO regulates normal pancreatic exocrine secretion, endocrine pancreatic insulin secretion and pancreatic micro vascular blood flow [30]. NO has been implicated as intercellular and intracellular messenger in a wide range of biologic processes, such as vasodilatation, platelet aggregation, neurotransmission, macrophage killing ability, and cell death [31]. Studies support the role of NO in the regulation of TG2 function in the extracellular environment [32]. NO is now accepted as a fundamental signaling molecule regulating virtually every critical cellular function, as well as a potent mediator of cellular damage in a wide range of conditions including cancer [33]. Studies have been done on different tissues which show that the NO donors inhibited transglutaminase catalytic activity [31,34,35]. $\mathrm{NO}$ is promising as an antineoplastic pharmacological agent due to its cytotoxicity [36]. Studies show that nitric oxide could induce the death of colon cancer cells [37]. NO produces multiple effects that can influence the outcome of tumor growth and metastasis. This molecule regulates vasodilatation and platelet aggregation which affect tumor cell arrest in capillaries. NO is also a major cytotoxic mediator secreted by activated macrophages and endothelial cells. It is shown to be responsible for the destruction of tumor cells passing through capillary beds. The production of endogenous NO is associated with apoptosis of tumorigenic cells [38]. Various direct and indirect mechanisms have been proposed for the anti-tumor properties of NO. Mechanisms include direct damage of DNA, inhibition of DNA synthesis and inhibition of the rate limiting enzyme ribonucleotide reductase. Reduced activity of cis-aconitase and loss of a large fraction of the iron pool, have also been suggested as possible mechanisms. Importantly, NO-generation can affect mitochondrial physiology leading to reduction of $\mathrm{O} 2$ consumption and damage to complexes I and II in the mitochondrial electron transport chain, reversible inhibition of complex IV activity and induction of apoptosis [39]. NO biology has provided the impetus for the development of anticancer agents based on their ability to release NO [40].

Nitroglycerin is a NO donor, its biological activity is by liberating NO [41-43]. The administration of NO-donating drugs decreased hypoxia-induced resistance to anticancer drugs in cancer cell lines. Studies have shown that Nitroglycerin may improve the response to chemotherapy in advanced non-small cell lung cancer [44,45]. NO donors such as nitroglycerin have been demonstrated to improve the effects of cancer therapy in solid cancers, promising therapeutic roles of $\mathrm{NO}$ and NO-donating drugs for novel treatments in solid tumors. There are studies which recommend clinical use of nitroglycerin as a novel cancer therapy in combination with anticancer drugs for improvement of cancer therapeutic levels [46].

S-nitroso-N-acetylpenicillamine is a NO donor $[47,48]$. Studies have suggested a regulatory role of $\mathrm{NO}$ or S-nitrosothiols on angiogenesis essential for melanoma growth [49]. Studies on ovarian cancer cells suggest that the NO donor S-nitroso-N-acetylpenicillamine (SNAP) induced apoptosis and also enhanced cisplatin-induced apoptosis in cisplatin-resistant human ovarian cancer cells [50].

Bacopa monnieri, which belongs to the family Scrophulariaceae and is a creeping annual plant found throughout the Indian subcontinent. It has been used by Ayurvedic medicinal practitioners in India for almost 3000 years and is classified as a medharasayana, a substance which improves memory and intellect [51]. It is a well-known medicinal herb. In the Indian system of medicine it is known as Brahmi (Sanskrit) and Indian water hyssop. Constituent Bacoside-A inhibits MMPs enzyme [52]. Bacoside-A exerts its anti-metastatic effect against Diethyl nitrosamine -induced hepatocellular carcinoma by inhibiting the activities and expressions of MMP-2 and MMP-9 [29].

Myricetin also is a major flavonoid found in several foods including onions, berries and grapes as well as red wine. Research data suggest that one of the major chemo preventive actions of myricetin could be related to its activity as an antioxidant. It has also been reported to suppress invasion and both protein expression and enzyme activity of matrix metalloproteinase- 2 in colorectal carcinoma cells. These accumulated data provide evidence that myricetin is a potent chemo preventive agent against carcinogenesis [53]. Studies reveal that Myricetin regulates MMP9 expression [54]. Myricetin has potent anticancer-promoting activity [53].

\section{Methods and Materials}

\section{Data set used for this in-silico study}

Protein involved in pancreatic cancer, Tissue Transglutaminase 
Citation: Desai NS, Gore M (2012) Computer Aided Drug Designing Using Phytochemicals- Bacoside A3 and Myricetin and Nitric Oxide DonorsS-Nitroso-N-Acetylpenicillamine and Nitroglycerin as a Potential Treatment of Pancreatic Cancer. J Comput Sci Syst Biol 5: 001-008. doi:10.4172/jcsb. 1000083

2 was taken for this work. Human Tissue Transglutaminase 2, with accession no - P21980.2 was taken from NCBI's entrez database. Templates used for homology modeling were taken from RCBS PDB database (information taken from Hhpred search) and were as follows-

a) 1 g0dA- (identity $=43 \%$, source=Pagrus major), 1 vjjA(identity $=39 \%$, source $=$ Homo sapiens), $1 \mathrm{ex} 0 \mathrm{~A}-($ identity $=38 \%$, source $=$ Homo sapiens)

b) Two other proteins implicated in pancreatic cancerMMP2 and MMP9 were also used for this study. Human Matrix metalloproteinase 2, with accession no - NP_001121363.1 and Matrix metalloproteinase 9, with accession no- NP_004985.2, were taken from NCBI's entrez database. Templates used for homology modeling were taken from RCBS PDB database (information taken from Hhpred search) and were as follows-

MMP2- 1fblA- (identity $=39 \%$, source $=$ Sus scrofa $), \quad 116 \mathrm{jA}-$ (identity $=59 \%$, source $=$ Homo sapiens), 3ba0A- (identity $=44 \%$, source $=$ Homo sapiens)

MMP9- 1ck7A (identity=48\%, source= Homo sapiens), $1 \mathrm{qhuA}$ (identity $=39 \%$, source $=$ Oryctolagus cuniculus), $1 \operatorname{slmA}$ (identity $=51 \%$, source $=$ Homo sapiens).

\section{Chemical structures}

The chemical structures used for this study were drawn using ACD chemsketch software (version 12.0.2). The structures were saved as *.mol file and were later converted to ${ }^{*}$.pdb file using Argus lab software (Table 1, Structure 1, Structure 2, Structure 3, Structure 4, Structure 5, Structure 6) (version 4.0.1). Chemical structures of Nitroglycerin,

\begin{tabular}{|c|c|c|}
\hline Chemical name & Chemsketch structure & Argus lab structure \\
\hline Nitroglycerin & (Structure 1) & (Structure 2) \\
\hline $\begin{array}{c}\text { S-nitroso-N- } \\
\text { acetylpenicillamine }\end{array}$ & (Structure 3) & (Structure 4) \\
\hline $\begin{array}{c}\text { Bacoside A3 and Myricetin } \\
\text { combination }\end{array}$ & (Structure 5) & (Structure 6) \\
\hline
\end{tabular}

Table 1: Chemical structures drawn using ACD/Chemsketch software and in Argus lab (*.pdb).<smiles>O=[N+]([O-])OCC(CO[N+](=O)[O-])O[N+](=O)[O-]</smiles>

(Structure 1)

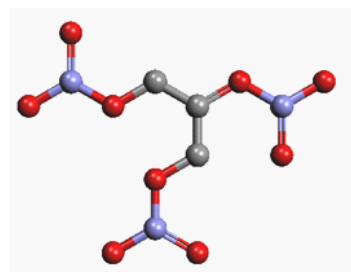

(Structure 2)<smiles>CC(=O)NC(C(=O)O)C(C)(C)SN=O</smiles>

(Structure 3)

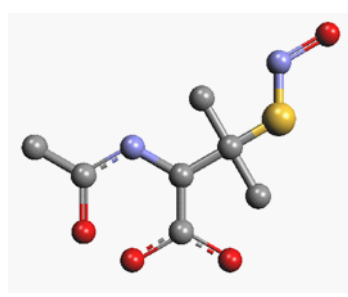

(Structure 4)

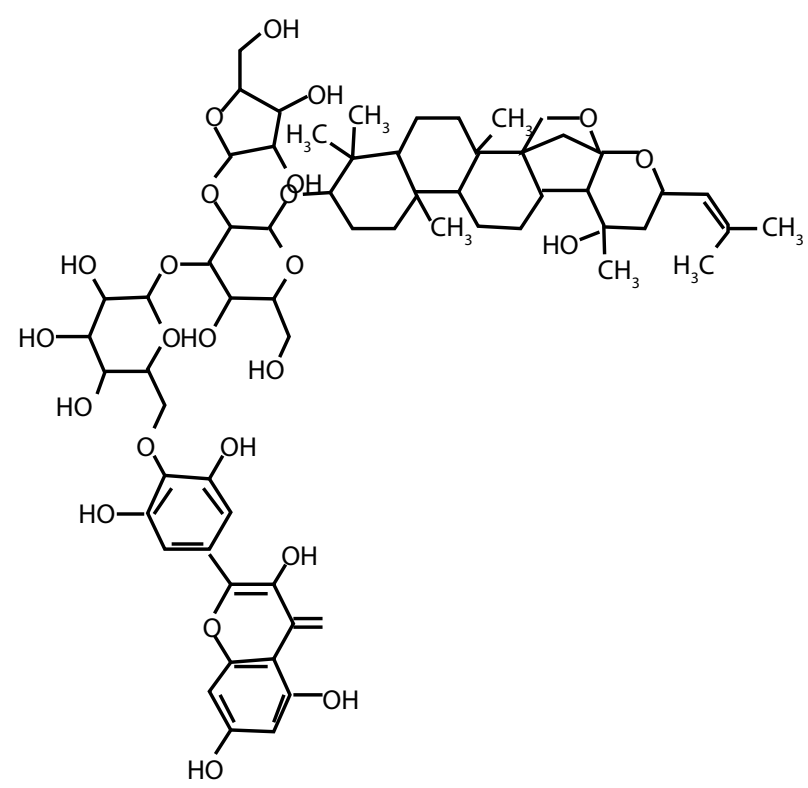

(Structure 5)

S-nitroso-N-acetylpenicillamine, Bacoside A3 and Myricetin were obtained from Pubchem of NCBI database.

\section{Homology modeling}

In silico methods can be used to predict a protein structure from amino acid sequence. Homology modelling involves prediction of the three dimensional structure of a protein from the known structures of one or more related proteins, which are used as templates. Modeller 9v7 is an automated program used for homology or comparative modeling of protein three-dimensional structures. The sequence to be modeled with known related structures is provided and Modeller 9v7 automatically predicts a three dimensional model of the unknown protein. The models obtained by using the software modeler $9 \mathrm{v} 7 \mathrm{can}$ be subjected to structural validation by assessment of the Ramachandran plot. The quality of a model can be judged, by detecting residues whose conformational angles lie outside allowed ranges. 
Citation: Desai NS, Gore M (2012) Computer Aided Drug Designing Using Phytochemicals- Bacoside A3 and Myricetin and Nitric Oxide DonorsS-Nitroso-N-Acetylpenicillamine and Nitroglycerin as a Potential Treatment of Pancreatic Cancer. J Comput Sci Syst Biol 5: 001-008. doi:10.4172/jcsb. 1000083

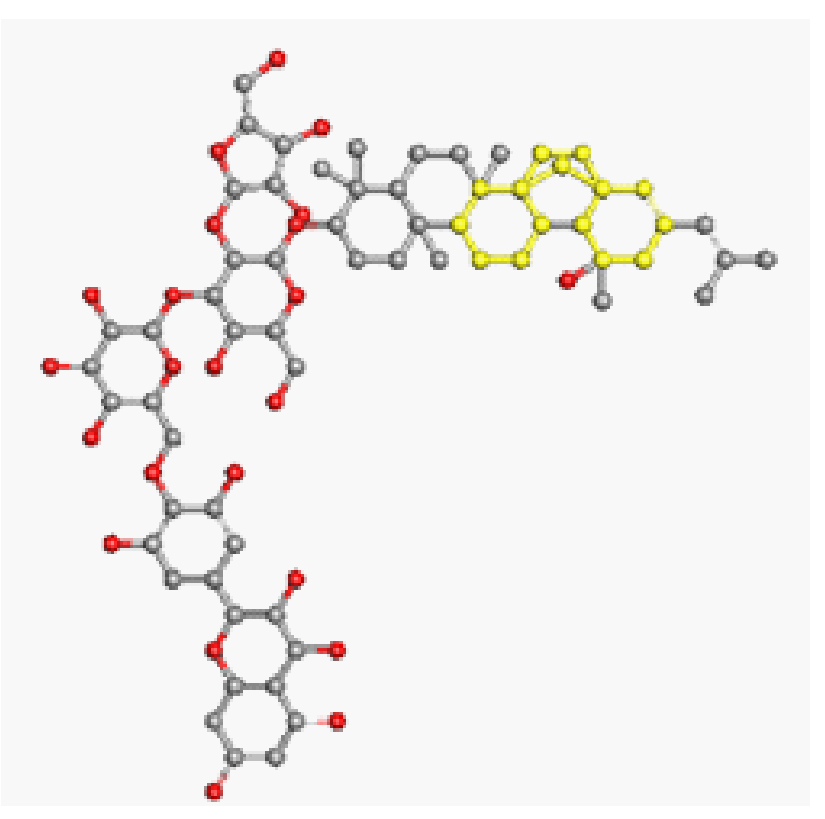

(Structure 6)

Homology modeling was carried out using Modeller 9v7, for predicting $3 \mathrm{D}$ structures for the above mentioned proteins. 5 models each, of the above proteins (TG2, MMP2, and MMP9) were generated. The models were analyzed by Rampage Ramachandran plot server and the best model of each of the proteins was selected.

\section{Docking}

Docking is a process, in which 2 molecules fit or dock together in a three dimensional space. Docking explores ways in which a target protein molecule and another molecule, such as drugs fit together. Hex docking software is an interactive protein docking and molecular superposition program. Hex understands protein and DNA structures in PDB format. HEX is a protein docking software used for molecular superimposition of various macromolecules.

Nitroglycerin: 3 D structure of protein Transglutaminase 2 was docked with nitroglycerin structure using Hex docking software (version 5.1).

S-nitroso-N-acetylpenicillamine: 3 D structure of protein Transglutaminase 2 was docked with S-nitroso-N-acetylpenicillamine structure using Hex docking software (version 5.1).

Myricetin and Bacoside A3 combination: $3 \mathrm{D}$ structures of proteins MMP2 and MMP9 were docked with structure of Myricetin and Bacoside A3 combination using Hex docking software (version 5.1).

\section{Results}

\section{Homology modeling}

3D structures of TG2, MMP2 and MMP9, obtained by homology modeling were analyzed by Rampage Ramachandran plot server. The results obtained for the best models are given in (Table 2, Chart 1 , Chart 2 and Chart 3).

\section{Docking}

The $3 \mathrm{D}$ structure of TG2 was successfully docked with nitroglycerin chemical structure. Visualization was done using Swiss pdb viewer.
Swiss-PdbViewer is an application that provides analysis of several proteins at the same time. The proteins can be superimposed in order to deduce structural alignments. It can be used as a visualization tool, to view docked molecules in a three dimensional space. The molecules can be highlighted and can be viewed as distinct entities. Thus the docking of the molecules can be visualized using SPDBV.

\section{The docking score as per patch dock server was- 3328}

PatchDock is an algorithm for molecular docking. It is a geometrybased molecular docking algorithm. It is aimed at finding docking transformations that yield good molecular shape complementarity. The input is two molecules in PDB format. The output contains the PDB files of the top scoring solutions [55] (Figure 1).

The 3 D structure of TG2 was successfully docked with S-nitroso$\mathrm{N}$-acetylpenicillamine chemical structure. The docking score as per patch dock server was- 3802 (Figure 2).

\begin{tabular}{|l|l|c|}
\hline Model ID & Result specifications & $\begin{array}{l}\text { Ramachandran } \\
\text { plot figure }\end{array}$ \\
\hline $\begin{array}{l}\text { Tissue } \\
\text { Transglutaminase }\end{array}$ & $\begin{array}{l}\text { Number of residues in favored region } \\
(\sim 98.0 \% \text { expected): } 659(96.2 \%) \text { Number } \\
\text { of residues in allowed region }(\sim 2.0 \% \\
\text { expected): } 23(3.4 \%) \text { Number of residues in } \\
\text { outlier region: 3 }(0.4 \%)\end{array}$ & (Chart 1) \\
\hline $\begin{array}{l}\text { Matrix } \\
\text { metalloproteinase } \\
2 \text { (model 5) }\end{array}$ & $\begin{array}{l}\text { Number of residues in favored region } \\
(\sim 98.0 \% \text { expected): 484 (79.6\%) Number } \\
\text { of residues in allowed region }(\sim 2.0 \% \\
\text { expected): } 76(12.5 \%) \text { Number of residues } \\
\text { in outlier region: 48 }(7.9 \%)\end{array}$ & (Chart 2) \\
\hline $\begin{array}{l}\text { Matrix } \\
\text { metalloproteinase } \\
9 \text { (model 3) }\end{array}$ & $\begin{array}{l}\text { Number of residues in favored region } \\
(\sim 98.0 \% \text { expected): } 639(90.6 \%) \text { Number } \\
\text { of residues in allowed region }(\sim 2.0 \% \\
\text { expected): 42 }(6.0 \%) \text { Number of residues in } \\
\text { outlier region : } 24(3.4 \%)\end{array}$ & (Chart 3) \\
\hline
\end{tabular}

Table 2: Analysis of best model for $3 \mathrm{D}$ structure of proteins using Rampage Ramachandran plot server.

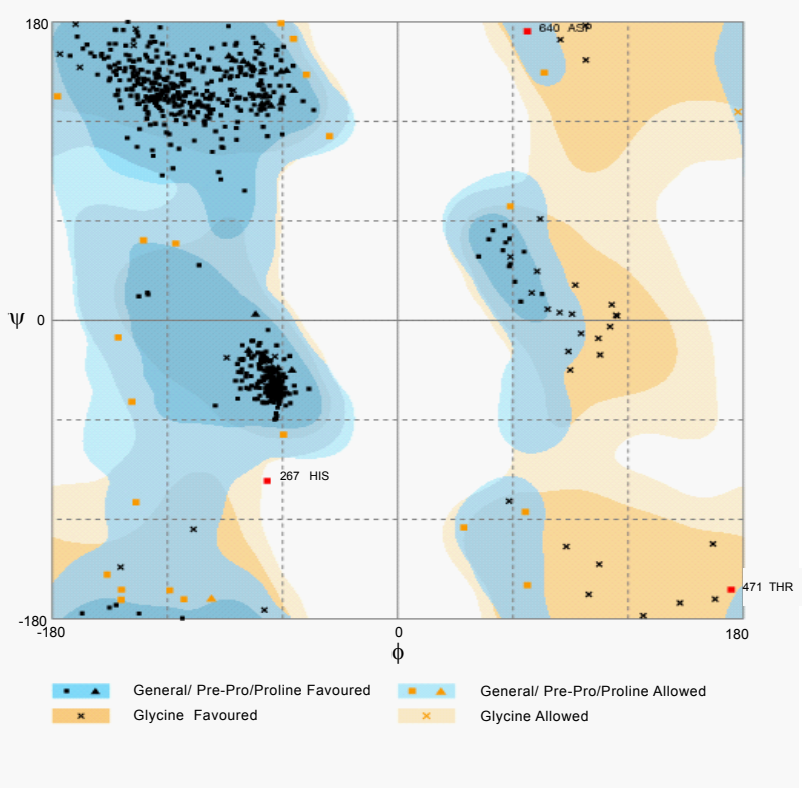

(Chart 1) 
Citation: Desai NS, Gore M (2012) Computer Aided Drug Designing Using Phytochemicals- Bacoside A3 and Myricetin and Nitric Oxide DonorsS-Nitroso-N-Acetylpenicillamine and Nitroglycerin as a Potential Treatment of Pancreatic Cancer. J Comput Sci Syst Biol 5: 001-008. doi:10.4172/jcsb.1000083

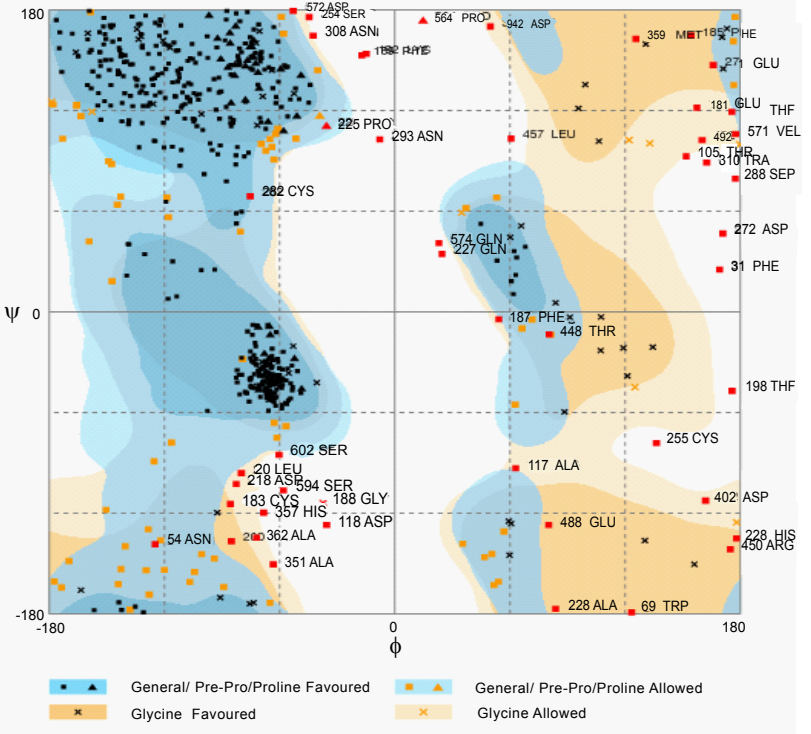

(Chart 2)

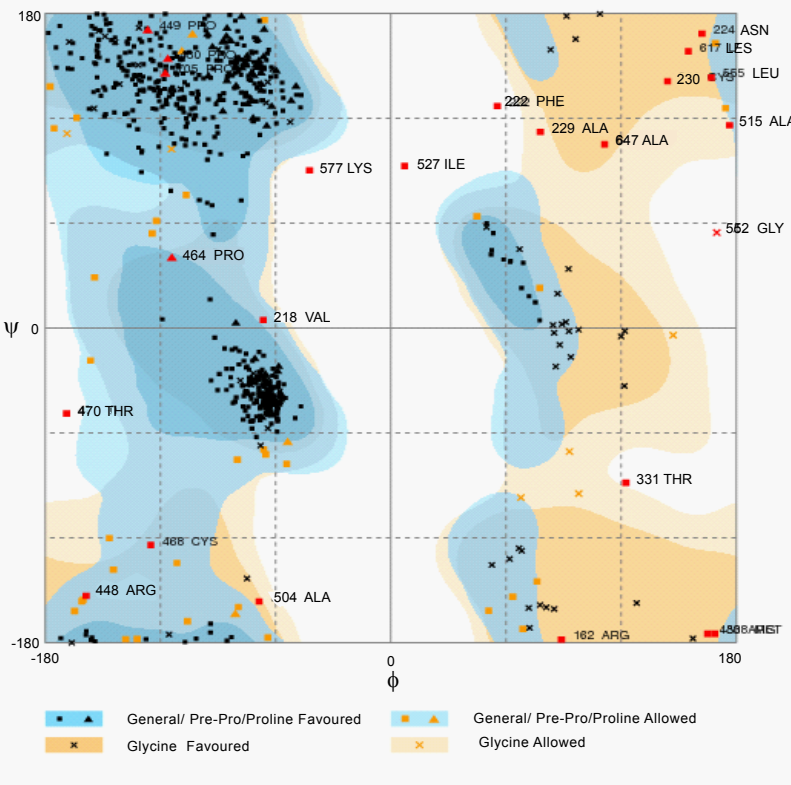

(Chart 3)

The 3 D structures of proteins- MMP2 and MMP9 were successfully docked with Bacoside A3 and Myricetin combination using Hex docking software. The docking scores as per patch dock server are-

Docking score of MMP2 with Bacoside A3 and Myricetin combination is 9276 (Figure 3)

Docking score of MMP9 with Bacoside A3 and Myricetin combination is 11180 (Figure 4)

\section{Conclusion}

This is an in-silico study, and using various bioinformatics tools, we have successful docked the $3 \mathrm{D}$ structure of protein tissue transglutaminase 2 with the chemical structures of nitric oxide donors $\mathrm{S}$-nitroso-N-acetylpenicillamine and nitroglycerin. This suggests that S-nitroso-N-acetylpenicillamine and nitroglycerin can be potential drugs for containment and treatment of pancreatic cancer which has a very poor prognosis.

Similarly, two other proteins implicated in pancreatic cancer, namely MMP2 and MMP9 have been successfully docked with

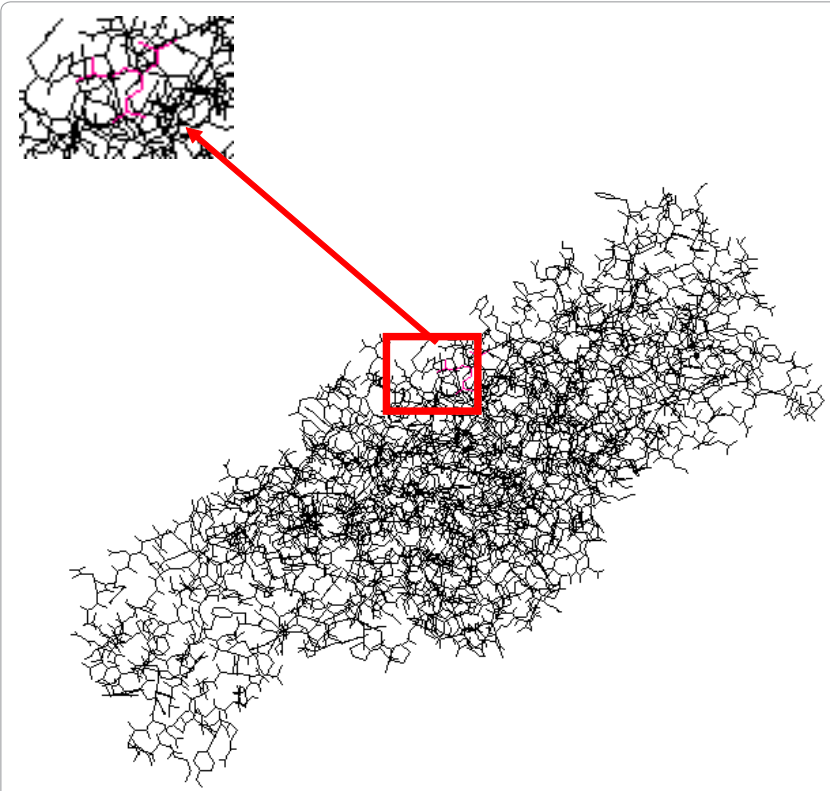

Figure 1: Docked structure of Transglutaminase 2 with nitroglycerin (visualization in SPDBV- version 4.0.1)

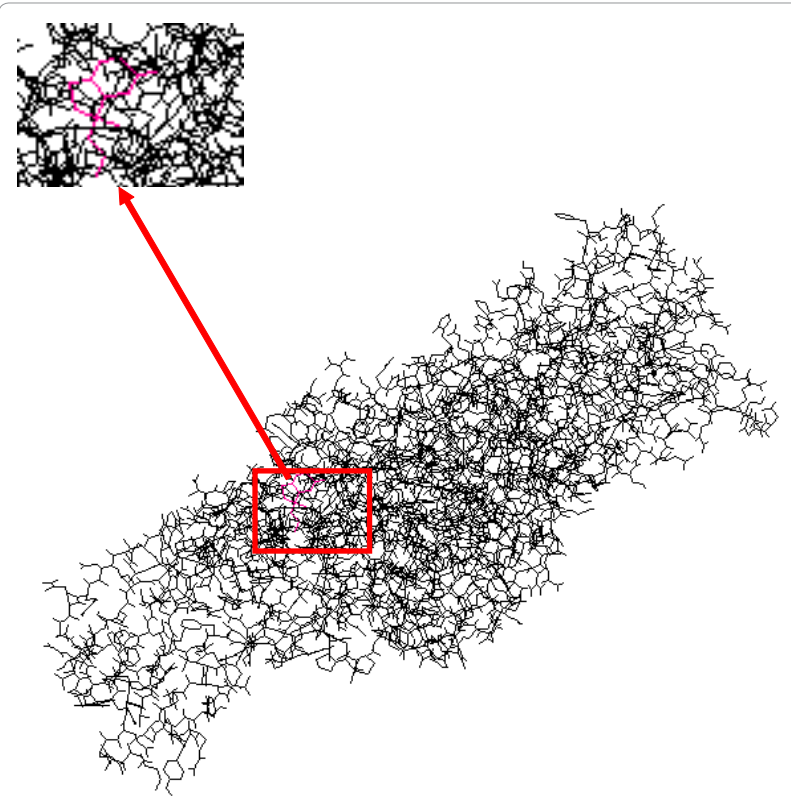

Figure 2: Docked structure of Transglutaminase 2 with S-nitroso-Nacetylpenicillamine (visualization in SPDBV, version 4.0.1). 
Citation: Desai NS, Gore M (2012) Computer Aided Drug Designing Using Phytochemicals- Bacoside A3 and Myricetin and Nitric Oxide DonorsS-Nitroso-N-Acetylpenicillamine and Nitroglycerin as a Potential Treatment of Pancreatic Cancer. J Comput Sci Syst Biol 5: 001-008. doi:10.4172/jcsb. 1000083

Bacoside A3- Myricetin combination structure, thus suggesting that this combination could be used for the containment of this aggressive cancer.

This in silico work comprises of computer aided drug designing, using which we suggest that nitric oxide donors- nitroglycerin and $\mathrm{S}$-nitroso-N-acetylpenicillamine can be used in the treatment of pancreatic cancer.

However, several lines of research have indicated that NO may have dual effects in cancer [39]. The biological effect of NO is dependent of the concentration at the site of action [41]. NO acts as an intracellular secondary messenger and provides an efficient system for cellular regulation, interaction and defense, while striking a very fine balance in its role in tumor growth and under some circumstances appearing to promote tumor growth, whereas other evidence suggests its production can be growth inhibitory. Low concentrations of NO can be pro-angiogenic and pro-tumor growth, whereas higher NO concentrations can have the opposite effect. Like many other areas of therapeutics, the concept of dose-response is very important $[38,56]$.

Hence the authors propose that further studies are required to identify the concentration of NO liberated by nitroglycerin and $\mathrm{S}$-nitroso-N-acetylpenicillamine for the containment of pancreatic cancer.

Studies have been done on Bacoside A3 and Myricetin suggesting their beneficial effect in certain cancers. Hence, Bacoside A3 and Myricetin combination structure was used for this study and was successfully docked with the proteins related to pancreatic cancer, namely MMP2 and MMP9.

Further in-vitro studies need to be done to establish the efficacy

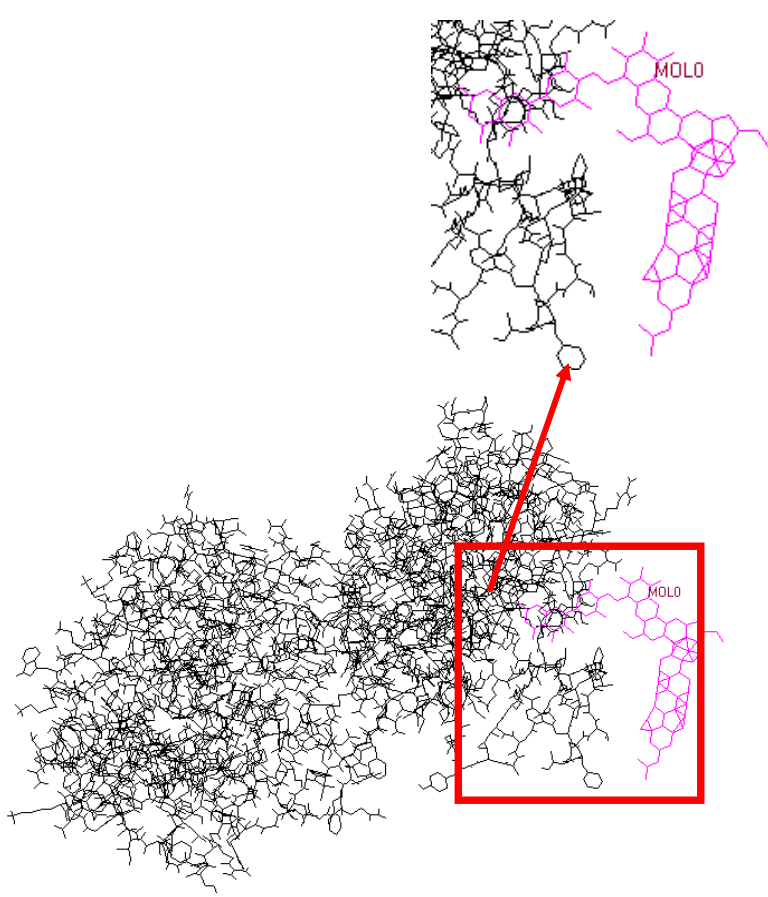

Figure 3: Docked structure of Matrix metalloproteinase 2 with Bacoside $\mathrm{A} 3$ and Myricetin combination (visualization in SPDBV, version 4.0.1).

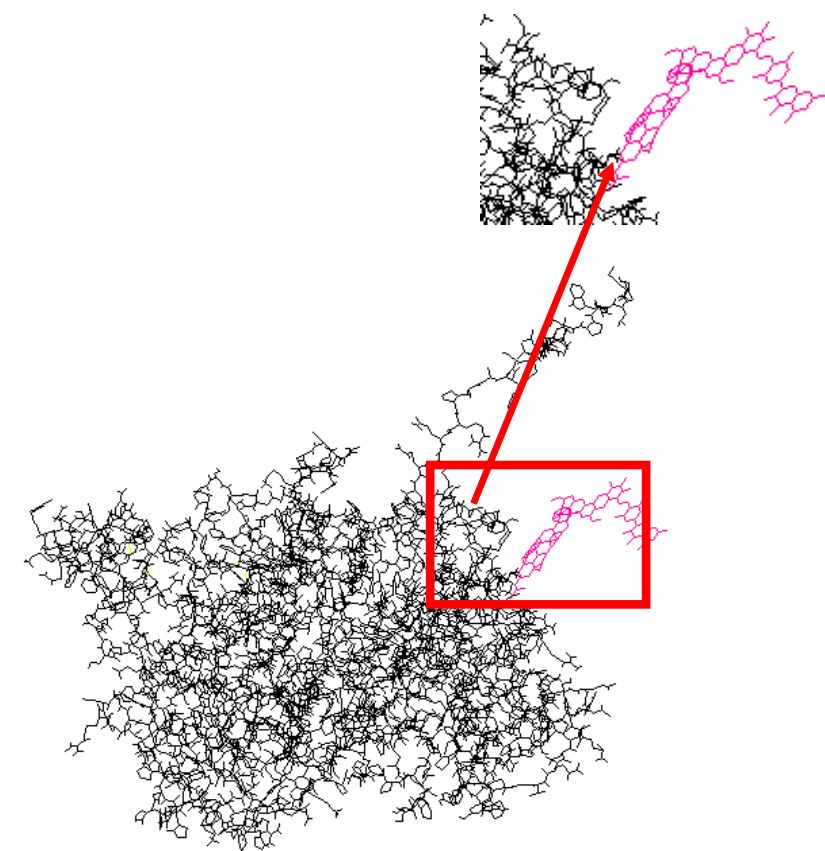

Figure 4: Docked structure of Matrix metalloproteinase 9 with Bacoside A3 and Myricetin combination (visualization in SPDBV, version 4.0.1).

of Bacoside A3 and Myricetin combination for the treatment of pancreatic cancer.

Computer aided drug designing is being extensively used to identify potential treatment for a number of diseases. There are numerous bioinformatics tools available which can be used to establish newer drugs for various diseases. Some of these tools were used in this study, to establish potential drugs for the treatment of pancreatic cancer. However, in-vitro and in-vivo studies are essential to verify the results obtained by using computer aided drug designing.

In this study, we have tried to establish potential treatment of pancreatic cancer, using nitroglycerin, $\mathrm{S}$-nitroso- $\mathrm{N}$-acetylpenicillamine, and myriceitn-bacoside A3 combination, using bioinformatics tools. As stated earlier, further in-vitro and in-vivo studies could be undertaken to prove the same.

\section{References}

1. Buchs NC, Chilcott M, Poletti PA, Buhler LH, Morel P (2010) Vascular invasion in pancreatic cancer: Imaging modalities, preoperative diagnosis and surgical management. World J Gastroenterol 16: 818-831.

2. Doi C, Egashira N, Kawabata A, Maurya DK, Ohta N, et al. (2010) Angiotensin II type 2 receptor signaling significantly attenuates growth of murine pancreatic carcinoma grafts in syngeneic mice. BMC Cancer 10: 67

3. Hezel AF, Kimmelman AC, Stanger BZ, Bardeesy N, Depinho RA (2006) Genetics and biology of pancreatic ductal adenocarcinoma. Genes Dev 20: 1218-1249.

4. Freelove R, Walling AD (2006) Pancreatic cancer: diagnosis and management Am Fam Physician 73: 485-492.

5. Hsieh MS, Liu KL, Tien YW, Shun CT (2009) Combined pancreatic endocrine tumor and serous cystadenoma. J Formos Med Assoc 108: 739-745.

6. Lee HY, Lee DG, Chun K, Lee S, Song SY (2009) Clear cell carcinoma of the pancreas -- a case report and review of the literature. Cancer Res Treat 41 175-181.

7. Bayraktar S, Bayraktar UD, Rocha-Lima CM (2010) Recent developments in 
Citation: Desai NS, Gore M (2012) Computer Aided Drug Designing Using Phytochemicals- Bacoside A3 and Myricetin and Nitric Oxide DonorsS-Nitroso-N-Acetylpenicillamine and Nitroglycerin as a Potential Treatment of Pancreatic Cancer. J Comput Sci Syst Biol 5: 001-008. doi:10.4172/jcsb.1000083

palliative chemotherapy for locally advanced and metastatic pancreas cancer. World J Gastroenterol 16: 673-682.

8. Cho K, Ishiwata T, Naito Z, Uchida E (2010) New therapeutic strategy for intractable pancreatic cancer and its fundamental research. J Nihon Med Sch 77: $62-63$.

9. Chue BM (2009) Five-year survival of metastatic pancreatic carcinoma: a study of courage and hope. Gastrointest Cancer Res 3: 208-211.

10. Velupillai P, Sung CK, Tian Y, Dahl J, Carroll J, et al. (2010) Polyoma virusinduced osteosarcomas in inbred strains of mice: host determinants of metastasis. PLoS Pathog 6: e1000733.

11. Saha A, Lee YC, Zhang Z, Chandra G, Su SB, et al. (2010) Lack of an endogenous anti-inflammatory protein in mice enhances colonization of B16F10 melanoma cells in the lungs. J Biol Chem 285: 10822-10831.

12. Verma A, Mehta K (2007) Tissue transglutaminase-mediated chemoresistance in cancer cells. Drug Resist Updat 10: 144-151.

13. Kim DS, Park SS, Nam BH, Kim IH, Kim SY (2006) Reversal of drug resistance in breast cancer cells by transglutaminase 2 inhibition and nuclear factorkappaB inactivation. Cancer Res 66: 10936-10943.

14. Mangala LS, Arun B, Sahin AA, Mehta K (2005) Tissue transglutaminaseinduced alterations in extracellular matrix inhibit tumor invasion. Mol Cancer 4:33.

15. Cao L, Petrusca DN, Satpathy M, Nakshatri H, Petrache I, et al. (2008) Tissue transglutaminase protects epithelial ovarian cancer cells from cisplatin-induced apoptosis by promoting cell survival signaling. Carcinogenesis 29: 1893-1900.

16. Herman JF, Mangala LS, Mehta K (2006) Implications of increased tissue transglutaminase (TG2) expression in drug-resistant breast cancer (MCF-7) cells. Oncogene 25: 3049-3058.

17. Fok JY, Ekmekcioglu S, Mehta K (2006) Implications of tissue transglutaminase expression in malignant melanoma. Mol Cancer Ther 5: 1493-1503.

18. Mehta K (2009) Biological and therapeutic significance of tissue transglutaminase in pancreatic cancer. Amino Acids 36: 709-716.

19. Verma A, Guha S, Diagaradjane P, Kunnumakkara AB, Sanguino AM, et al. (2008) Therapeutic significance of elevated tissue transglutaminase expression in pancreatic cancer. Clin Cancer Res 14: 2476-2483.

20. Elsässer HP, MacDonald R, Dienst M, Kern HF (1993) Characterization of a transglutaminase expressed in human pancreatic adenocarcinoma cells. Eur J Cell Biol 61: 321-328.

21. Ozpolat B, Akar U, Mehta K, Lopez-Berestein G (2007) PKC delta and tissue transglutaminase are novel inhibitors of autophagy in pancreatic cancer cells. Autophagy 3: 480-483

22. Verma A, Wang $H$, Manavathi B, Fok JY, Mann AP, et al. (2006) Increased expression of tissue transglutaminase in pancreatic ductal adenocarcinoma and its implications in drug resistance and metastasis. Cancer Res 66: 1052510533

23. Fracalossi AC, Miranda SR, Oshima CT, Franco M, Ribeiro DA (2010) The role of matrix metalloproteinases 2 and 9 during rat tongue carcinogenesis induced by 4-nitroquinoline 1-oxide. J Mol Histol 41: 19-25.

24. Zucker S, Cao J (2009) Selective matrix metalloproteinase (MMP) inhibitors in cancer therapy: ready for prime time? Cancer Biol Ther 8: 2371-2373.

25. Berger T, Cheung CC, Elia AJ, Mak TW (2010) Disruption of the Lcn2 gene in mice suppresses primary mammary tumor formation but does not decrease lung metastasis. Proc Natl Acad Sci U S A 107: 2995-3000.

26. Szarvas T, Becker M, vom Dorp F, Gethmann C, Tötsch M, et al. (2010) Matrix metalloproteinase-7 as a marker of metastasis and predictor of poor survival in bladder cancer. Cancer Sci 101: 1300-1308.

27. Mroczko B, Łukaszewicz-Zajac M, Guzińska-Ustymowicz K, Gryko M, Czyzewska J, et al. (2009) Expression of matrix metalloproteinase-9 in the neoplastic and interstitial inflammatory infiltrate cells in gastric cancer. Folia Histochem Cytobiol 47: 491-496.

28. Escaff S, Fernández JM, González LO, Suárez A, González-Reyes S, et al. (2010) Study of matrix metalloproteinases and their inhibitors in prostate cancer. Br J Cancer 102: 922-929.

29. Janani P, Sivakumari K, Geetha A, Yuvaraj S, Parthasarathy C (2010) Bacoside A downregulates matrix metalloproteinases 2 and 9 in DEN-induced hepatocellular carcinoma. Cell Biochem Funct 28: 164-169.

30. DiMagno MJ (2007) Nitric oxide pathways and evidence-based perturbations in acute pancreatitis. Pancreatology 7: 403-408.

31. Rossi A, Catani MV, Candi E, Bernassola F, Puddu P, et al. (2000) Nitric oxide inhibits cornified envelope formation in human keratinocytes by inactivating transglutaminases and activating protein 1. J Invest Dermatol 115: 731-739.

32. Telci D, Collighan RJ, Basaga H, Griffin M (2009) Increased TG2 expression can result in induction of transforming growth factor beta1, causing increased synthesis and deposition of matrix proteins, which can be regulated by nitric oxide. J Biol Chem 284: 29547-29558.

33. Kozoni V, Rosenberg T, Rigas B (2007) Development of novel agents based on nitric oxide for the control of colon cancer. Acta Pharmacol Sin 28: 1429-1433.

34. Haroon ZA, Wannenburg T, Gupta M, Greenberg CS, Wallin R , et al. (2001) Localization of Tissue Transglutaminase in Human Carotid and Coronary Artery Atherosclerosis: Implications for Plaque Stability and Progression. Lab Invest 81: 83-93.

35. Bakker EN, Buus CL, Spaan JA, Perree J, Ganga A, et al. (2005) Small Artery Remodeling Depends on Tissue-Type Transglutaminase. Circ Res 96: 119 126.

36. Edes K, Cassidy P, Shami PJ, Moos PJ (2010) JS-K, a nitric oxide prodrug has enhanced cytotoxicity in colon cancer cells with knockdown of thioredoxin reductase 1. PLoS One 5: e8786.

37. Prévotat L, Filomenko R, Solary E, Jeannin JF, Bettaieb A (2006) Nitric oxideinduced down-regulation of beta-catenin in colon cancer cells by a proteasomeindependent specific pathway. Gastroenterology 131: 1142-1152.

38. Alexandrova R, Mileva M, Zvetkova E (2001) Nitric oxide and cancer (Minireview). Experimental Pathology and Parasitology 4: 13-18.

39. Xu W, Liu LZ, Loizidou M, Ahmed M, Charles IG (2002) The role of nitric oxide in cancer. Cell Res 12: 311-320.

40. Rigas B. (2007) Novel agents for cancer prevention based on nitric oxide Biochem Soc Trans 35: 1364-1368.

41. Agvald P, Adding LC, Artlich A, Persson MG, Gustafsson LE (2002) Mechanisms of nitric oxide generation from nitroglycerin and endogenous sources during hypoxia in vivo. Br J Pharmacol 135: 373-382.

42. Chung SJ, Chong S, Seth P, Jung CY, Fung HL (1992) Conversion of nitroglycerin to nitric oxide in microsomes of the bovine coronary artery smooth muscle is not primarily mediated by glutathione-S-transferases. J Pharmaco Exp Ther 260: 652-659.

43. Ghatta S, O'Rourke ST (2006) Nitroglycerin-induced release of calcitonin generelated peptide from sensory nerves attenuates the development of nitrate tolerance. J Cardiovasc Pharmacol 47:175-181.

44. Yasuda H, Nakayama K, Watanabe M, Suzuki S, Fuji $H$, et al. (2006) Nitroglycerin treatment may enhance chemosensitivity to docetaxel and carboplatin in patients with lung adenocarcinoma. Clin Cancer Res 12:67486757.

45. Yasuda H, Yamaya M, Nakayama K, Sasaki T, Ebihara S, et al. (2006) Randomized phase II trial comparing nitroglycerin plus vinorelbine and cisplatin with vinorelbine and cisplatin alone in previously untreated stage IIIB/IV nonsmall-cell lung cancer. J Clin Oncol 24: 688-694.

46. Yasuda H (2008) Solid tumor physiology and hypoxia-induced chemo/radioresistance: novel strategy for cancer therapy: nitric oxide donor as a therapeutic enhancer. Nitric Oxide 19: 205-216

47. Sano H, Hirai M, Saito H, Nakashima I, Isobe KI (1997) A nitric oxidereleasing reagent, S-nitroso- $\mathrm{N}$-acetylpenicillamine, enhances the expression of superoxide dismutases mRNA in the murine macrophage cell line RAW264-7. Immunology 92: 118-122.

48. Park YK, Ahn DR, Oh M, Lee T, Yang EG, et al. (2008) Nitric oxide donor, 
Citation: Desai NS, Gore M (2012) Computer Aided Drug Designing Using Phytochemicals- Bacoside A3 and Myricetin and Nitric Oxide DonorsS-Nitroso-N-Acetylpenicillamine and Nitroglycerin as a Potential Treatment of Pancreatic Cancer. J Comput Sci Syst Biol 5: 001-008. doi:10.4172/jcsb. 1000083

(+/-)-S-nitroso-N-acetylpenicillamine, stabilizes transactive hypoxia-inducible factor-1alpha by inhibiting von Hippel-Lindau recruitment and asparagine hydroxylation. Mol Pharmacol 74: 236-245.

49. Paschoalin T, Carmona AK, Rodrigues EG, Oliveira V, Monteiro HP, et al. (2007) Characterization of thimet oligopeptidase and neurolysin activities in B16F10-Nex2 tumor cells and their involvement in angiogenesis and tumor growth. Mol Cancer 6: 1476-4598.

50. Leung EL, Fraser M, Fiscus RR, Tsang BK (2008) Cisplatin alters nitric oxide synthase levels in human ovarian cancer cells: involvement in p53 regulation and cisplatin resistance. $\mathrm{Br} \mathrm{J}$ Cancer 98: 1803-1809.

51. Deb DD, Kapoor P, Dighe RP, Padmaja R, Anand MS, et al. (2008) In vitro safety evaluation and anticlastogenic effect of BacoMind on human lymphocytes. Biomed Environ Sci 21: 7-23.

52. Sharath R, Harish BG, Krishna V, Sathyanarayana BN, Swamy HM (2010)
Wound healing and protease inhibition activity of Bacoside-A, isolated from Bacopa monnieri wettest. Phytother Res 8: 1217-1222.

53. Lee KW, Kang NJ, Rogozin EA, Kim HG, Cho YY, et al. (2007) Myricetin is a novel natural inhibitor of neoplastic cell transformation and MEK1. Carcinogenesis 28: 1918-1927.

54. Jung SK, Lee KW, Kim HY, Oh MH, Byun S, et al. (2010) Myricetin suppresses UVB-induced wrinkle formation and MMP-9 expression by inhibiting Raf Biochem Pharmacol 79: 1455-1461.

55. Schneidman-Duhovny D, Inbar Y, Nussinov R, Wolfson HJ (2005) Patch Dock and SymmDock: servers for rigid and symmetric docking. Nucleic Acids Res 33(Web Server issue): W363-W367.

56. Chinje EC, Stratford IJ (1997) Role of nitric oxide in growth of solid tumours: a balancing act. Essays Biochem 32: 61-72. 